\title{
Numerical models sea surface wind compared to scatterometer observations for a single Bora event in the Adriatic Sea
}

\author{
F. De Biasio, M. M. Miglietta, S. Zecchetto, and A. della Valle \\ Institute of Atmospheric Sciences and Climate, Italian National Research Council, Corso Stati Uniti 4, \\ 35127 Padova, Italy \\ Correspondence to: F. De Biasio (f.debiasio@isac.cnr.it)
}

Received: 15 January 2014 - Revised: 31 March 2014 - Accepted: 2 April 2014 - Published: 15 May 2014

\begin{abstract}
We compare the sea surface wind fields forecasted by a Global Circulation Model (GCM) and three Limited Area Models (LAMs) in an operational-like set-up, with the wind remotely sensed by the NASA QuikSCAT scatterometer. The comparison is performed for a single case of Bora wind in the Adriatic Sea, with the purpose to understand the ability of the model forecasts in reproducing the mesoscale features captured by the scatterometer, and to investigate on the suitability of LAM and GCM forecasts as possible forcing in storm surge models (SSMs). The performance is evaluated by means of statistical parameters regarding wind speed and direction showing that, at least in terms of classical statistical parameters, the GCM offer the most advantageous choice in terms of cost/benefit.
\end{abstract}

\section{Introduction}

An open question for Numerical Weather Prediction (NWP) modelling is how atmospheric fields simulated by Global Circulation Models (GCMs) and Limited Area Models (LAMs) compare to observations, and how the wind field in presence of complex orography are represented. On the marine environment, satellite-borne scatterometers offer a huge number of observations of the so called "ocean wind vector" (OWV), which expresses the wind blowing at the sea surface. OWV observations are essential to describe the state of the bottom layer of the atmosphere and to forecast the state of the atmosphere and the underlying sea surface. The sea is, thus, an important test-site for model performance, particularly when enclosed and semi-enclosed basins surrounded by complex orography are considered, because the model performance is affected by the interaction of the flow with both the sea surface and the orography. This is of particular interest for the Adriatic Sea, where specific synoptic configurations, combined with the local orography (Zecchetto et al., 2012; Zecchetto and Accadia, 2014), often cause atmospheric conditions favourable to high water levels at the sea boundaries, particularly in the Venice Lagoon, whose loca- tion in the Adriatic Sea is shown in the left panel of Fig. 1. NWP models are used to simulate the atmospheric fields, and their output variables are used as forcing to storm surge models in order to forecast the sea level therein.

The objective of this work is to compare the $10 \mathrm{~m}$ wind fields simulated by four NWP models with the OWV provided by the NASA QuikSCAT scatterometer, in view of a possible use of the models as forcing in storm surge modelling systems. Here we start from a single case study of interest for the Adriatic Sea. The four NWP models are the Integrated Forecast System (IFS), the operational GCM of the European Centre for Medium-Range Weather Forecasts (ECMWF), and three different LAMs: ALADIN, COSMOLAMI and the Weather Research and Forecasting (WRF).

Previous works comparing scatterometer observations and NWP model forecasts were based on the analysis of a high number of observed and simulated collocated data, providing monthly-seasonal statistics. Accadia et al. (2007) analysed the seasonal fields of several statistics parameters, using two years of QuikSCAT L2B $25 \mathrm{~km}$ observations and the wind field forecasts produced by the Quadrics Bologna Limited-Area Model (QBOLAM) over the Mediterranean Sea on a $0.1^{\circ} \times 0.1^{\circ}$ regular grid. They found areas of lower 


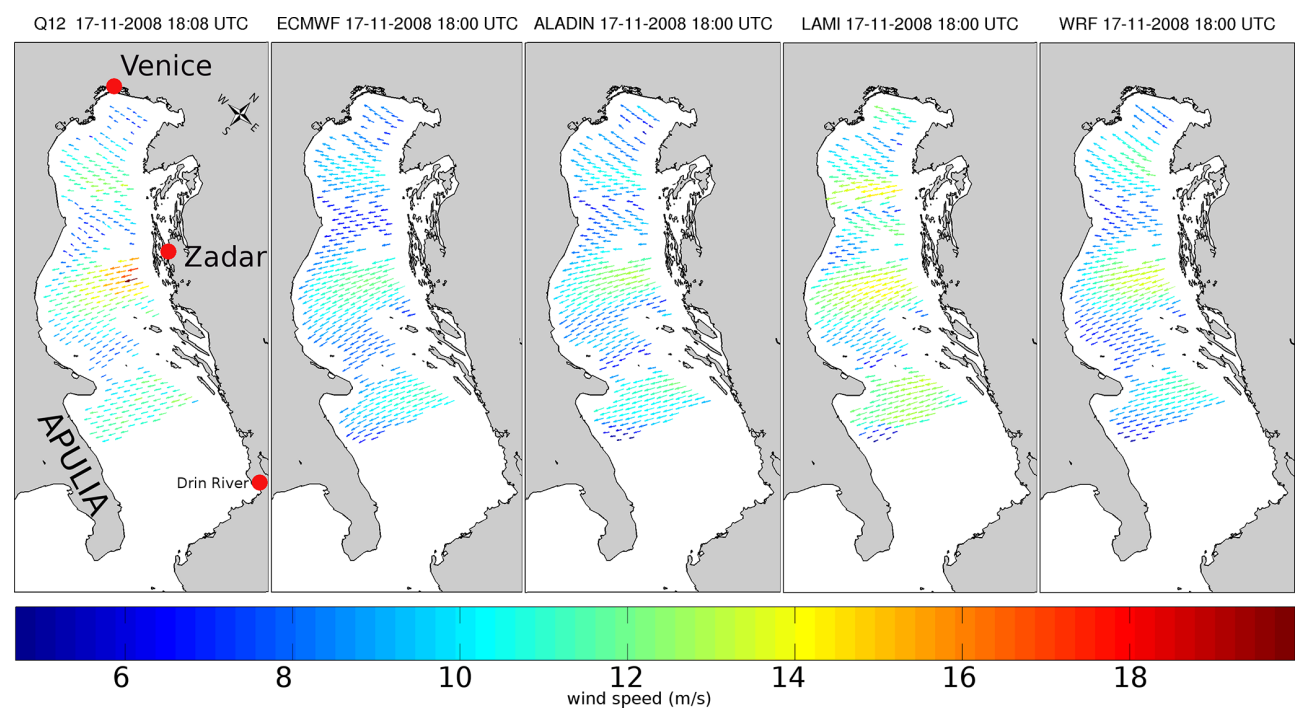

Figure 1. Sea surface wind fields on 17 November. From left to right: the scatterometer pass at 18:08 UTC, and the models wind fields (ECMWF, ALADIN, COSMO-LAMI, WRF) at 18:00 UTC. The maps are rotated $40^{\circ}$ clockwise. The colourbar corresponds to the wind intensity, in $\mathrm{m} \mathrm{s}^{-1}$, of the vectors plotted in the maps. The first map on the left shows also the geographic positions of Venice (Italy), Zadar (Croatia), the Drin River (Albania) and Apulia region (Italy). The title of the fourth map from left should be read "COSMO-LAMI".

than average forecast skill, identified as semi-enclosed basins surrounded by rough orography. The discrepancies found between model forecasts and scatterometer observations were ascribed mainly to three factors; the representation of the orography in the model; the numerical damping required for computational stability (resulting in a model spatial resolution coarser than the nominal grid size); other forecast errors, which are associated with the spatial and temporal misplacement of the meteorological phenomena (fronts, depressions, etc.) and the misrepresentation of data needed by the model as initial or boundary conditions (e.g. imposing constant sea surface temperature fields during the model run).

Kara et al. (2009) compared, on a monthly basis, the QuikSCAT $25 \mathrm{~km}$ data with "analysis quality" NWP winds (A. Wallcraft, personal communication, 2014) coming from the NOGAPS dataset at $0.5^{\circ}$-resolution, in the Mediterranean Sea. They found major differences near coastal boundaries due to contamination of model winds over sea by land data, as a consequence of the coarse resolution of the model.

In our study we focused on the comparison of model data and scatterometer winds on a per-swath basis, in a single case of bora wind (17-18 November 2008) in the Adriatic Sea (Fig. 1), with the objective of operational SSM applications, keeping the scatterometer wind as the reference field.

The paper is organised as follows. The instruments and the methods are described in Sect. 2. Section 3 presents the case study, followed by the discussion in Sect. 4 . The conclusions are drawn in Sect. 5.

\section{Instruments and methods}

\subsection{Scatterometer data and preparation of the dataset}

Scatterometers are active microwave instruments providing measurements of the wind field over the ocean. In this work we use the OWV fields at $10 \mathrm{~m}$ over the sea with a grid spacing of $12.5 \mathrm{~km}$, provided by the SeaWinds scatterometer onboard the NASA QuikSCAT satellite (Dunbar et al., 2006), available from 1999 to 2009 and processed by the SeaWinds Processing and Analysis Center (SeaPAC) at the Jet Propulsion Laboratory (JPL).

Operating in Ku-band, the data retrieved by SeaWinds could be contaminated by rain. However, the rainfall rate records at several ground stations along the coast of the Adriatic Sea in the present case were from zero to extremely low, so that the scatterometer data were completely retained. The swath of QuikSCAT is $1800 \mathrm{~km}$ wide: data corresponding to wind cells at nadir and at the outer sides of the swath have been discarded, since in these regions have lower quality and more noise. Only winds in the range $3-25 \mathrm{~m} \mathrm{~s}^{-1}$ have been used for comparison.

The accuracy of the QuikSCAT winds at $25 \mathrm{~km}$ grid spacing has been investigated, among several authors, by Ebuchi et al. (2002), which reported uncertainties of $\pm 1.01 \mathrm{~ms}^{-1}$ and of $\pm 23^{\circ}$ respectively for wind speed and direction in open ocean. Tang et al. (2004) evaluated the high-resolution L2B QuikSCAT OWV at $12.5 \mathrm{~km}$ grid spacing data also in coastal regions, and reported a slight deterioration of the accuracies in the proximity of the coastline: $\pm 1.70 \mathrm{~ms}^{-1}$ in speed and $\pm 26^{\circ}$ in direction for wind speed $>3 \mathrm{~m} \mathrm{~s}^{-1}$. 
Table 1. LAMs set-up.

\begin{tabular}{|c|c|c|c|c|c|c|c|c|}
\hline & $\begin{array}{l}\text { Nominal } \\
\text { grid }(\mathrm{km})\end{array}$ & $\begin{array}{l}\text { Time step } \\
\text { (hours) }\end{array}$ & $\begin{array}{l}\text { Initial/boundary } \\
\text { conditions }\end{array}$ & $\begin{array}{l}\text { Microphysics } \\
\text { scheme }\end{array}$ & $\begin{array}{l}\text { Radiation } \\
\text { scheme }\end{array}$ & $\begin{array}{l}\text { Closure } \\
\text { scheme }\end{array}$ & Orography & $\begin{array}{l}\text { Convection } \\
\text { scheme }\end{array}$ \\
\hline ALADIN & 8 & 1 & $\begin{array}{l}\text { ARPEGE } \\
\text { analysis/ } \\
\text { forecast }\end{array}$ & ALARO0 & $\begin{array}{l}\text { Geleyn- } \\
\text { Hollingworth } \\
\text { radiation }\end{array}$ & $\begin{array}{l}1.5 \text { order } \\
\text { closure } \\
\text { turbulence }\end{array}$ & $\begin{array}{l}\text { land-surface } \\
\text { ISBA scheme }\end{array}$ & $\begin{array}{l}\text { modified } \\
\text { Bougeault } \\
(1985)\end{array}$ \\
\hline COSMO-LAMI & 7 & 1 & $\begin{array}{l}\text { ECMWF } \\
\text { analysis/ } \\
\text { forecast }\end{array}$ & bulk & $\begin{array}{l}\text { Ritter-Geleyn } \\
\text { radiation }\end{array}$ & $\begin{array}{l}\text { TKE Mellor- } \\
\text { Yamada } 2.5 \\
\text { order }\end{array}$ & $\begin{array}{l}\text { Terra land } \\
\text { surface }\end{array}$ & Tiedtke \\
\hline WRF & 10 & 1 & $\begin{array}{l}\text { ECMWF } \\
\text { analysis/ } \\
\text { forecast }\end{array}$ & $\begin{array}{l}\text { Thompson et } \\
\text { al. (2004) }\end{array}$ & Kain cumulus & $\begin{array}{l}\text { Yonsei } \\
\text { University } \\
\text { (YSU) } \\
\text { boundary layer }\end{array}$ & $\begin{array}{l}\text { Unified Noah } \\
\text { land-surface } \\
\text { model }\end{array}$ & $\begin{array}{l}\text { Rapid } \\
\text { Radiative } \\
\text { Transfer Model }\end{array}$ \\
\hline
\end{tabular}

Winds fields provided by scatterometers are given for neutral stability conditions. While in the open ocean the stability conditions are close to neutral (Chelton and Freilich, 2005), in the Mediterranean Sea, on average, they range from neutral to unstable (Zecchetto and De Biasio, 2007). The correction of scatterometer winds from neutral to real stability conditions affects mainly low winds, implying a reduction of $20-30 \%$ for unstable conditions and an increase of $+20 \%$ for stable conditions in the Mediterranean Sea (Zecchetto and De Biasio, 2007). To compare scatterometer data with model winds, the adjustment can be done in two ways: modifying the scatterometer values to real stability conditions, or viceversa, adjusting model winds to neutral stability. As we have in mind real applications, we consider the former approach. The adjustment is calculated with the model of Liu et al. (1979), which requires, as input, the air and dew point temperatures, the sea-surface temperature and the atmospheric pressure at sea level. All these parameters have been derived from the ECMWF analysis fields.

\subsection{Atmospheric model data}

In this section we present the NWP models used for the comparison. They are briefly described below. More details on the LAMs set-up and characteristics are reported in Table 1.

\subsubsection{The ECMWF operational global circulation model}

The ECMWF operational forecast model, known as Integrated Forecast System (Simmons et al., 1989), is a global spectral model that produces deterministic forecasts up to 15 days in advance.

For the case considered here, the model implementation includes 91 vertical levels and horizontal truncation level 799 (TL799, approximately $25 \mathrm{~km}$ ). The model output fields are available every $3 \mathrm{~h}$. For the sake of comparison, in this study we use the forecast produced at 12:00 UTC the day before each temporal match-up. The parameters used are the $10 \mathrm{~m}$ $U$ and $V$ wind components. One may object that the comparison with QuikSCAT is not fair, since global models assim- ilate QuikSCAT data. Anyway, the effective horizontal resolution of the scatterometer data used for the assimilation in the ECMWF model was about $100 \mathrm{~km}$ (Stoffelen and Anderson, 1997), which is too coarse for an effective modification of the mesoscale fields in the analysis over the Adriatic sea; also, the fields used for the comparison are the $24 \mathrm{~h}$ forecasts, which are only marginally affected by the assimilation of wind data over sea surface. Moreover, the three LAMs use ARPEGE and ECMWF IFSs as initial and boundary conditions, so that the supposed advantage given by QuikSCAT assimilation into GCMs is shared with LAMs too.

\subsubsection{The ALADIN model}

ALADIN (Aire Limitée Adaptation dynamique Développement InterNational; Bubnova et al., 1995) is a limited-area spectral high-resolution model, nested into the ARPEGE (Action de Recherche Petite Echelle Grande Echelle) IFS GCM. It has been mainly developed at Météo-France in cooperation with ECMWF. The sea surface wind fields used in this work are the results of operational simulations at DHZ (Državni Hidrometeorološki Zavod), the meteo-hydrological service of Croatia.

\subsubsection{The COSMO-LAMI model}

The COSMO model (Steppeler et al., 2003) is a limited area model developed and maintained by national and regional European meteorological services members of the Consortium for Small-scale Modeling (COSMO). A particular set up, called COSMO-LAMI (Limited Area Model Italy), is run operationally by the Agenzia Regionale per la Prevenzione e Protezione Ambientale-Servizio Idro Meteo Clima (ARPASIMC) of the Emilia Romagna Region.

\subsubsection{The WRF model}

The WRF model (see http://www.wrf-model.org; Wang et al., 2010) is a numerical weather prediction system designed to serve both operational forecasting and atmospheric 
Table 2. Statistical parameters of the five wind datasets for the two passes, on 17 November (left) and 18 November (right) 2008. The statistical parameters are the mean wind direction and speed with their standard deviations $(\sigma)$, and root mean square error (RMSE), bias, centred root mean square difference (cRMSD) and correlation coefficient $(R)$ of the model wind speed with respect to the scatterometer observations. In bold the best scores.

\begin{tabular}{|c|c|c|c|c|c|c|c|c|c|c|c|c|c|c|c|c|}
\hline & \multicolumn{8}{|c|}{17 November } & \multicolumn{8}{|c|}{18 November } \\
\hline & $\begin{array}{r}\langle w \operatorname{dir}\rangle \\
\left({ }^{\circ}\right)\end{array}$ & $\begin{array}{r}\sigma_{\text {wdir }} \\
\left({ }^{\circ}\right)\end{array}$ & $\begin{array}{c}\langle\mathrm{ws}\rangle \\
\left(\mathrm{m} \mathrm{s}^{-1}\right)\end{array}$ & $\begin{array}{r}\sigma_{\mathrm{ws}} \\
\left(\mathrm{m} \mathrm{s}^{-1}\right)\end{array}$ & $\begin{array}{r}\mathrm{RMSE}_{\mathrm{ws}} \\
\left(\mathrm{m} \mathrm{s}^{-1}\right)\end{array}$ & $\begin{array}{r}\operatorname{bias}_{\mathrm{ws}} \\
\left(\mathrm{m} \mathrm{s}^{-1}\right)\end{array}$ & $\begin{array}{r}\mathrm{cRMSD}_{\mathrm{ws}} \\
\left(\mathrm{m} \mathrm{s}^{-1}\right)\end{array}$ & $R_{\mathrm{ws}}$ & $\begin{array}{r}\langle\text { wdir }\rangle \\
\left({ }^{\circ}\right)\end{array}$ & $\begin{array}{r}\sigma_{\text {wdir }} \\
\left({ }^{\circ}\right)\end{array}$ & $\begin{array}{c}\langle\mathrm{ws}\rangle \\
\left(\mathrm{m} \mathrm{s}^{-1}\right)\end{array}$ & $\begin{array}{r}\sigma_{\mathrm{ws}} \\
\left(\mathrm{m} \mathrm{s}^{-1}\right)\end{array}$ & $\begin{array}{r}\mathrm{RMSE}_{\mathrm{ws}} \\
\left(\mathrm{m} \mathrm{s}^{-1}\right)\end{array}$ & $\begin{array}{r}\operatorname{bias}_{\mathrm{ws}} \\
\left(\mathrm{m} \mathrm{s}^{-1}\right)\end{array}$ & $\begin{array}{r}\mathrm{cRMSD}_{\mathrm{ws}} \\
\left(\mathrm{m} \mathrm{s}^{-1}\right)\end{array}$ & $R_{\mathrm{ws}}$ \\
\hline QUIK SCAT & 48.3 & 19.4 & 10.65 & 2.00 & - & - & - & - & 45.4 & 14.1 & 8.15 & 2.95 & - & - & - & - \\
\hline ECMWF & 39.0 & 16.9 & 9.27 & 1.36 & 1.91 & 1.38 & 1.32 & 0.75 & 31.2 & 22.5 & 6.79 & 2.05 & 2.31 & 1.36 & 1.87 & 0.78 \\
\hline ALADIN & 46.6 & 18.5 & 9.49 & 1.53 & 1.96 & 1.16 & 1.57 & 0.63 & 33.8 & 17.5 & 7.74 & 2.63 & 2.15 & 0.41 & 2.11 & 0.72 \\
\hline COSMO-LAMI & 43.5 & 15.7 & 11.03 & 1.93 & 1.87 & -0.37 & 1.83 & 0.57 & 49.7 & 27.4 & 9.17 & 3.62 & 2.83 & -1.02 & 2.64 & 0.69 \\
\hline WRF & 47.7 & 17.4 & 9.51 & 1.79 & 2.01 & 1.15 & 1.65 & 0.63 & 39.9 & 19.6 & 7.93 & 2.19 & 1.67 & 0.22 & 1.66 & 0.83 \\
\hline
\end{tabular}

research needs, mainly developed at the National Center for Atmospheric Research (NCAR). The version 3.0 of the model, already implemented at the ISAC-CNR facilities, has been used for this study in a single grid configuration. The current configuration uses 40 vertical levels, more closely spaced in the boundary layer.

\subsection{Temporal and spatial collocation}

The scatterometer pass time has been identified as the reference time. Then the wind fields of the four models at the synoptic hour closer to the pass time have been used for the match-up, thus allowing a maximum time difference of $\pm 1.5 \mathrm{~h}$.

Scatterometer data have been interpolated on a regular grid of $0.125^{\circ}$ by $0.125^{\circ}$, to compare with the ECMWF wind. The interpolation method is pure Laplacian, to avoid excessive data smoothing: it has been demonstrated not to change the wind speed and direction statistics (Accadia et al., 2007). LAMs winds have been mapped to the same grid with the nearest neighbour algorithm. After interpolation, only data points farther than $15 \mathrm{~km}$ from the coast, the nominal distance for the QuikSCAT $12.5 \mathrm{~km}$ dataset, have been retained, using for this purpose the Global 30 Arc-Second Elevation (GTOPO30) digital elevation model of the U.S. Geological Survey, which has an accuracy of about $1 \mathrm{~km}$.

\section{The Bora case}

We focused the comparison on a case of Bora wind in the Adriatic Sea during 17 to 18 November 2008. Bora (Yoshino, 1976; Jurčec, 1981; Smith, 1987; Pandžić and Likso, 2005), is a north-easterly strong and cold wind affecting the entire Adriatic Sea. Atkinson (1989) classified this wind as orographic or downslope. It is generally due to a polar high over the plateau behind the Dinaric Alps and a pressure low farther south over the warmer Adriatic Sea. Such a meteorological situation favours the funnelling of the stratified cold air behind the Dinaric Alps through the mountain chain gaps towards the Adriatic basin.

The scatterometer passes over the area considered for comparison with the NWP model fields are at 18:08 UTC on 17 November, and 03:50 UTC on 18 November. Consequently, the model outputs have been extracted at 18:00 UTC on 17 November, and 03:00 UTC on 18 November.

At the first pass (Fig. 1, left), the scatterometer data shows an intense north-easterly flow across the Adriatic sea, with a maximum of about $20 \mathrm{~m} \mathrm{~s}^{-1}$ to the west of the Croatian coast near Zadar (Zadar is shown with a red mark in Fig. 1). Two additional but weaker low level jets are identified in the northern and southern part of the Adriatic sea. All the models are able to capture these features pretty well, being the WRF model wind the closest to that of the scatterometer; a slight underestimation of the wind speed occurs for all the models, apart from COSMO-LAMI, which slightly overestimates the northern and the southern jets. Wind roses (not shown) confirm the good performance of the models in reproducing the wind intensity and direction. The statistical parameters in Table 2 show that LAMs generally perform better than ECMWF model in terms of wind direction and intensity (for ECMWF IFS, the wind is weaker and slightly rotated anticlockwise).

The relative frequency of wind speed bins (not shown) has similar distribution for ECMWF, ALADIN and WRF, which slightly underestimate the scatterometer data, while COSMO-LAMI is shifted towards higher values of wind speed bins.

Similar considerations can be drawn at the later pass, when the Bora structures shift southward (Fig. 2). At that time, the most intense jet blows across the southern Adriatic, from the valley of Drin river towards Apulia (south-eastern Italy); the jet across Zadar is still present, but slightly weaker and less extensive than eight hours earlier; a third, weaker jet can be identified in between these two features.

Again, COSMO-LAMI overestimates the wind speed, especially the two southernmost jets, and the wind speed frequency is shifted towards higher bins (not shown), but the distribution in terms of average wind direction is the closest to that of the scatterometer (see Table 2), although standard deviation is the highest; ECMWF significantly underestimates the wind speed and distributes the wind over a narrower range of speed bins. 


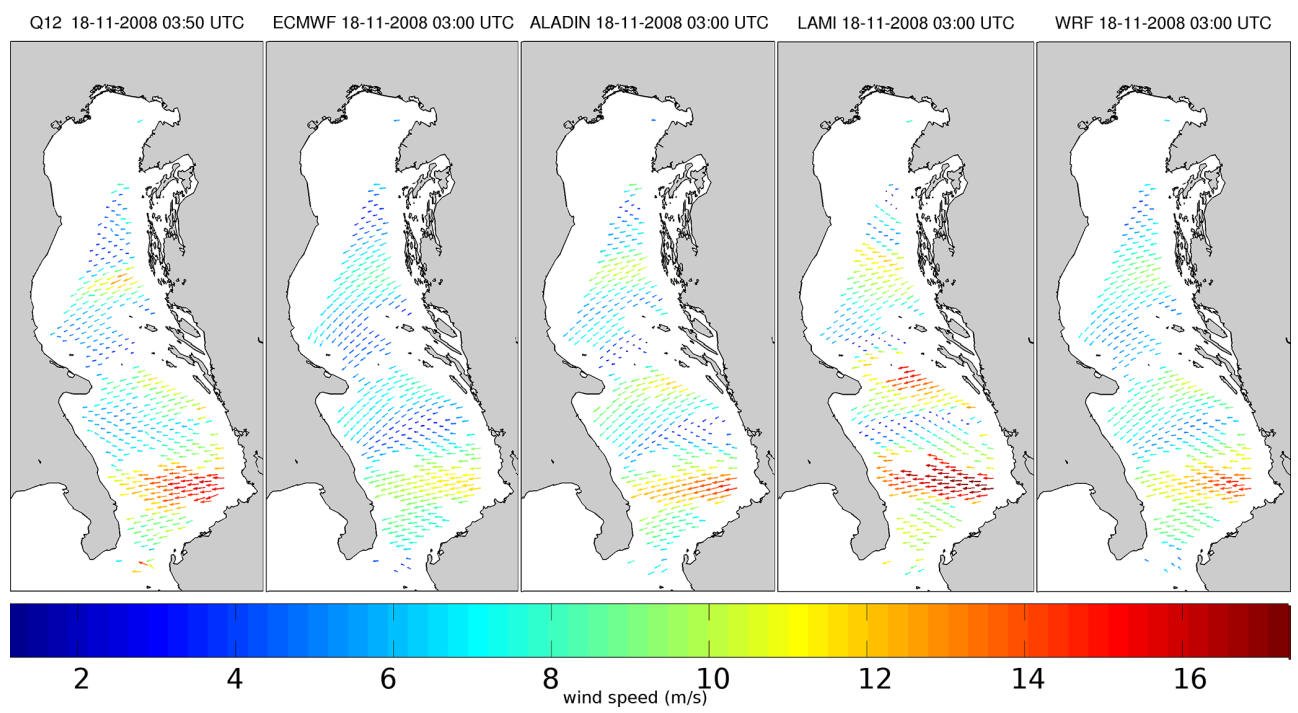

Figure 2. Sea surface wind fields on 18 November. From left to right: the scatterometer pass at 03:50 UTC, and the models wind fields (ECMWF, ALADIN, COSMO-LAMI, WRF) at 03:00 UTC. The maps are rotated $40^{\circ}$ clockwise. The colorbar corresponds to the wind intensity, in $\mathrm{m} \mathrm{s}^{-1}$, of the vector plots in the maps.

\section{Discussion}

The spatial scales typical of storm surges in the Adriatic Sea are rather large, as a consequence of the large temporal scales (hours) of the phenomenon, due to the dependence of the local storm surge level on the wind stress over the entire Adriatic Sea. In the perspective of SSM operational applications, scatterometer data are appropriate tools: SeaWinds, as well as ASCAT and OSCAT, the nowadays operational scatterometer sensors, provide data in the Mediterranean Sea twice a day, ensuring the possibility to follow the evolution of meteorological phenomena with time scales of some hours, and their distribution is relatively fast and free of charge.

From a statistical point of view, however, the spatial and temporal sampling of the Adriatic Sea surface wind by scatterometer observations accounts for more than $90 \%$ of the wind energy of the statistically significant mean wind field (Zecchetto and Cappa, 2001), assuring that scatterometer observations supply an adequate description of the structure of the sea surface wind up to spatial scales in the meso-beta range (Orlanski, 1975).

On the other hand, satellite-borne Synthetic Aperture Radars (SAR), have a much finer spatial resolution (from metres to hundreds of metres, depending on the sensor); however, their images are not frequent; their acquisition has often to be agreed in advance with the space agencies; the use of their full spatial resolution would be unpractical for operational use; finally, there is no standard SAR wind product operationally provided by the agencies: the algorithms to extract the wind direction from them are still in a development phase and depend on external sources of information (Zecchetto and De Biasio, 2008).
As explained before, scatterometer data have been corrected for stability making use of ECMWF analyses. As Bora wind transports cold air over the Adriatic Sea, the stability conditions were unstable during the case study: the ECMWF mean air-sea temperature difference were respectively $-3.2^{\circ}$ $\mathrm{C}$ and $-5.3{ }^{\circ} \mathrm{C}$ during the two scatterometer passes. Consequently, the bias between stability-corrected winds and neutral winds was $-0.19 \mathrm{~m} \mathrm{~s}^{-1}$ during the first pass and -0.34 $\mathrm{m} \mathrm{s}^{-1}$ during the second. These biases are not particularly large, but are comparable to the model biases (see Table 2), and thus have to be taken into account. This is even more important considering that the storm surge depends linearly on the wind stress, which depends from the squared wind speed.

A possible source of error could be the ability of the scatterometer to accurately record high and low wind speeds. The scatterometer data used in this work are in the wind speed range suitable to assure the nominal accuracy. This is evident in Fig. 3, which reports the scatterplots of scatterometer and model wind speeds, for the pass of 17 November (left) and 18 November (right). During the first pass the scatterometer wind speeds are concentrated in the range $6-17 \mathrm{~m} \mathrm{~s}^{-1}$, with some outliers at $20 \mathrm{~m} \mathrm{~s}^{-1}$. Model data are in the range 4-14 $\mathrm{m} \mathrm{s}^{-1}$. During the second pass the wind speed ranges are more broadened, with the scatterometer data between 3 and $16 \mathrm{~m} \mathrm{~s}^{-1}$, and the model data between 1 and $17 \mathrm{~m} \mathrm{~s}^{-1}$. In both scatterplots all the best-fits are far from the perfect agreement, apart from that of the COSMO-LAMI model in the second passage. This should be ascribed to the particular basin chosen for the comparison and its rough orography, and for the proximity of all the collocation points to the coastline.

Table 2 shows the modelled statistical parameters for the two passes in comparison with the scatterometer data. At the 

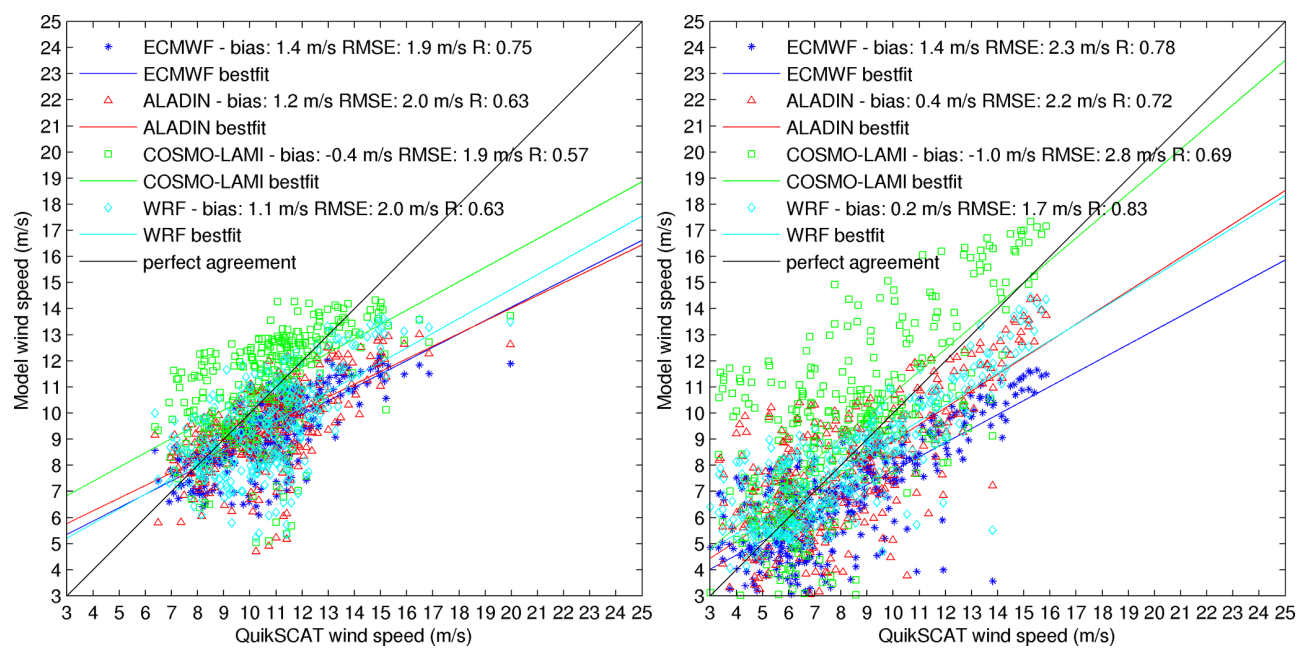

Figure 3. Scatterplot of the wind speed of the QuikSCAT scatterometer and the four NWP models for the satellite passes of 17 November (left) and 18 November (right). The legends report the bias, the RMSE and the correlation coefficient of the models with respect to the scatterometer observations. In black solid the perfect agreement line.

first pass, ECMWF has the largest correlation coefficient $(R)$, but the worst bias, and the standard deviation $(\sigma)$ is strongly underestimated. COSMO-LAMI, which is the only model overestimating the wind speed, has at this time the smallest bias, the best $\sigma$ and the smallest root mean square error (RMSE); WRF and ALADIN behave similarly, with bias and centred root mean square difference (cRMSD: it is the RMSE calculated on the unbiased datasets) very close to those of ECMWF model. At later time (right panel), WRF outperforms the other models in terms of $R$, cRMSD, RMSE and bias. ALADIN shows a slightly worse $R$ (but still larger than 0.7 ), and has the $\sigma$ most similar to the scatterometer data. As a consequence of the overestimation (bias $=-1.02 \mathrm{~m} \mathrm{~s}^{-1}$ ) of the low level jets, COSMO-LAMI has the largest $\sigma$ and the smallest $R$. Finally, although ECMWF strongly underestimates the wind speed and $\sigma$, it has still one of the largest $R$.

Really, the traditional statistical indices should be taken into consideration with caution. For example, the forecast of a jet predicted with the correct intensity but with a slightly wrong timing and location, is worse in terms of correlation than the forecast of a global model, which predicts a smoother jet in the correct location, but is definitely much more skilful for a forecaster (Miglietta et al., 2012). Thus, a smooth forecast can lead to better verification statistics than a forecast with a correct amplitude in structural features (Warner, 2011). This aspect is also highlighted by Signell et al. (2005), who conducted extensive comparison of NWP forecast wind fields from a GCM and three LAMs of different spatial resolution with in-situ data. They found that the temporal correlation between in-situ data and GCM was better than with LAMs, and ascribed this result to the fact that large-scale features can be predicted in a deterministic way (the GCM nominal grid size was $40 \mathrm{~km}$ ), while small-scale features are stochastic, and their prediction can thus be misrepresented in time and space, especially by LAMs.

About the significance of traditional statistical indices, a special attention should be paid to the wind speed $\sigma$. Skamarock (2004), analysing the deviation of NWP model spectra from the theoretical behaviour, estimated that the NWP models effective resolution resulted to be several times larger than their nominal resolution. Therefore, given a modelled $\sigma$ comparable to that of the observations, it is fair to expect that part of the signal in $\sigma$ is due to model noise, and thus the effective $\sigma$, due to the modelled geophysical signal, should be lower. With this observation in mind it is clear that the comparison of the model $\sigma$ with that of observations has to be considered cautiously.

\section{Conclusions}

This study compares the wind speed and direction retrieved from the scatterometer in a Bora event across the Adriatic sea with the wind simulated with four different models, i.e. a global circulation model and three limited area models. All the models are able to reproduce the different wind patterns emerging in the scatterometer wind field at two different passes, but with some differences. The global model (ECMWF IFS) is the best in terms of correlation, but it suffers from a larger bias (underestimation) and a reduced variability (smaller standard deviation). COSMO-LAMI is the only model among the four to overestimate, on average, the wind speed and produces the largest standard deviation; it is the worst model in terms of correlation. Generally, ALADIN and WRF behave in an intermediate way between the former two models. Being comparable with the other model statistics, the ECMWF model results as the best candidate for operational SSM applications in terms of cost/benefit, based 
on this statistical analysis. Such results should be tested in a longer time period to verify if they are statistically robust. A work is in progress to compare the scatterometer data with two different operational limited area models and one global circulation model over a three-year period.

Acknowledgements. The QuikSCAT SeaWinds ocean wind vector data were obtained from the Physical Oceanography Distributed Active Archive Center (PO.DAAC) at the NASA Jet Propulsion Laboratory, Pasadena, CA (http://podaac.jpl.nasa.gov).

The ECMWF GCM fields were obtained from ECMWF by mean of the Meteorological Service of Aeronautica Militare.

The ALADIN and COSMO-LAMI wind fields have been supplied by the Istituzione Centro Previsioni e Segnalazioni Maree (ICPSM) of the Venice Municipality.

Edited by: A. M. Sempreviva

Reviewed by: two anonymous referees

\section{References}

Accadia, C., Zecchetto, S., Lavagnini, A., and Speranza, A.: Comparison of 10-m wind forecasts from a regional area model and QuikSCAT scatterometer wind observations over the Mediterranean Sea, Mon. Weather Rev., 135, 1946-1960, 2007.

Atkinson, B. W.: Meso-scale atmospheric circulation. Academic Press, Harcourt Brace Jovanovich Publishers, London, UK, 1989.

Bougeault, P.: A simple parameterization of the large-scale effects of cumulus convection, Mon. Weather Rev., 113, 2108-2121, 1985.

Bubnova, R. , Hello, G., Benard, P., and Geleyn, J. F., Integration of the fully elastic equations cast in the hydrostatic pressure terrainfollowing coordinate in the framework of the ARPEGE/Aladin NWP System, Mon. Weather Rev., 123, 515-535, 1995.

Chelton, D. B. and Freilich, M. H.: Scatterometer-based assessment of 10-m wind analyses from the operational ECMWF and NCEP numerical weather prediction models, Mon. Weather Rev., 133, 409-429, 2005.

Dunbar, R. S., Lungu, T., Weiss, B., Stiles, B., Huddleston, J., Callahan, P. S., Shirtliffe, G., Perry, K. L., Hsu, C., Mears, C., Wentz, F., and Smith, D.: QuikSCAT Science Data Product Users Manual, Version 3.0, Jet Propulsion LaBoratory, Pasadena, CA, JPL Document D-18053-Rev A, 2006.

Ebuchi, N., Graber, H. C., and Caruso, M. J.: Evaluation of Wind Vectors Observed by QuikSCAT/SeaWinds Using Ocean Buoy Data, J. Atmos. Ocean. Tech., 19, 2049-2062, doi:10.1175/15200426(2002)019<2049:EOWVOB>2.0.CO;2, 2002.

Jurčec, V.: On mesoscale characteristics of Bora conditions in Yugoslavia, Pure Appl. Geophys., 199, 640-657, 1981.

Kara, A. B., Wallcraft, A. J., Martin, P. J., and Pauley, R. L.: Optimizing surface winds using QuikSCAT measurements in the Mediterranean Sea during 2000-2006, J. Mar. Syst., 78, 119131, doi:10.1016/j.jmarsys.2007.11.010, 2009.

Liu, W. T., Katsaros, K. B., and Businger, J. A.: Bulk parametrizations of air-sea exchanges of heat and water vapor including the molecular constraints at the interface, J. Atmos. Sci., 36, 1722$1735,1979$.
Miglietta, M. M., Thunis, P., Pederzoli, A., Georgieva, E., Bessagnet, B., Terrenoire, E., and Colette, A.: Evaluation of WRF model performances in different European regions with the DELTAFAIRMODE evaluation tool, Int. J. Environ. Pollut., 50, 83-97, 2012.

Orlanski, I.: A rational subdivision of scales for atmospheric processes, B. Am. Meteorol. Soc., 56, 527-530, 1975.

Pandžić, K. and Likso, T.: Eastern Adriatic typical wind field patterns and large-scale atmospheric conditions, Int. J. Climatol., 25, 81-98, 2005.

Signell, R., Carniel, S., Cavaleri, L., Chiggiato, J., Doyle, J., Pullen, J., and Sclavo, M.: Assessment of wind quality for oceanographic modeling in semi-enclosed basins, J. Mar. Syst., 53, 217-233, 2005.

Simmons, A. J., Burridge, D. M., Jarraud, M., Girardm, M., and Wergen, W.: The ECMWF medium-range prediction model's development of the numerical formulations and the impact of increased resolution, Meteorol. Atmos. Phys., 40, 28-60, 1989.

Skamarock, W. C.: Evaluating Mesoscale NWP Models Using Kinetic Energy Spectra, Mon. Weather Rev., 132, 3019-3032, 2004.

Smith, R. B.: Aerial characteristics of Yugoslavian Bora, J. Atmos. Sci., 44, 2934-2939, 1987.

Steppeler, J., Doms, G., Schättler, U., Bitzer, H. W., Gassmann, A., Damrath, U., and Gregoric, G.: Meso-gamma scale forecasts using the nonhydrostatic model LM, Meteorol. Atmos. Phys., 82, 75-96, 2003.

Stoffelen, A. and Anderson, D.: Ambiguity removal and assimilation of scatterometer data, Q. J. Roy. Meteorol. Soc., 123, 491518, 1997.

Tang, W. Q., Liu, W. T., and Stiles, B. W.: Evaluation of highresolution ocean surface vector winds measured by QuikSCAT scatterometer in coastal regions, IEEE T. Geosci. Remote, 42, 1762-1769, 2004.

Thompson, G., Rasmussen, R. M., and Manning, K.: Explicit forecasts of winter precipitation using an improved bulk microphysics scheme. Part I: Description and sensitivity analysis, Mon. Weather Rev., 132, 519-544, 2004.

Wang, W., Bruyère, C., Duda, M., Dudhia, J., Gill, D., Lin, H.-C., Michalakes, J., Rizvi, S., and Zhang, X.: ARW Version 3 Modelling System User's Guide, 312 pp., NCAR, Boulder, Colorado, 2010.

Warner, T. T.: Numerical Weather and Climate Prediction, Cambridge University Press, 548 pp., 2011.

Yoshino, M.: Local wind Bora, University of Tokyo Press, Tokyo, Japan, 1976.

Zecchetto, S. and Cappa, C., The spatial structure of the Mediterranean Sea winds revealed by ERS-1 scatterometer, Int. J. Remote Sens., 22, 45-70, doi:10.1080/014311601750038848, 2001.

Zecchetto, S. and De Biasio, F.: Sea Surface Winds over the Mediterranean Basin from Satellite Data (2000-04): Meso- and Local-Scale Features on Annual and Seasonal Time Scales, J. Appl. Meteor. Climatol., 46, 814-827, doi:10.1175/JAM2498.1, 2007.

Zecchetto, S. and De Biasio, F.: A Wavelet-Based Technique for Sea Wind Extraction from SAR Images, IEEE T. Geosci. Remote, 46, 2983-2989, doi:10.1109/TGRS.2008.920967, 2008. 
Zecchetto, S. and Accadia, C.: Diagnostics of T1279 ECMWF analysis winds in the Mediterranean basin by comparison with ASCAT $12.5 \mathrm{~km}$ winds, Q. J. Roy. Meteorol. Soc., published online in Wiley Online Library, doi:10.1002/qj.2315, 2014.
Zecchetto, S., De Biasio, F., and Accadia, C.: Scatterometer and ECMWF derived wind vorticity over the Mediterranean Basin, Q. J. Roy. Meteorol. Soc., 139, 674-684, doi:10.1002/qj.2001, 2012. 